\title{
Light-Emitting Electrochemical Cells of Single Crystal Hybrid Halide Perovskite with Vertically Aligned Carbon Nanotubes Contacts
}

\author{
Pavao Andričević, ${ }^{\dagger}$ Xavier Mettan, ${ }^{\dagger}$ Márton Kollár, $^{\dagger}$ Bálint Náfrádi, $^{\dagger}{ }^{\dagger}$ Andrzej Sienkiewicz, ${ }^{\dagger} \ddagger$ (i)
} Tonko Garma, ${ }^{\S}$ Lidia Rossi, $^{\dagger}$ László Forró, $^{*}{ }^{\dagger}$ and Endre Horváth* ${ }^{*} \dagger(0$

${ }^{\dagger}$ Laboratory of Physics of Complex Matter (LPMC), Ecole Polytechnique Fédérale de Lausanne, Centre Est, Station 3, CH-1015 Lausanne, Switzerland

${ }^{\ddagger}$ ADSresonances SARL, Route de Genève 60B, CH-1028 Préverenges, Switzerland

${ }^{\S}$ Power Engineering Department, Faculty of Electrical Engineering, Mechanical Engineering and Naval Architecture, University of Split, Split, Croatia

\section{Supporting Information}

ABSTRACT: Based on the reported ion migration under an electric field in hybrid lead halide perovskites we have developed a bright, light-emitting electrochemical cell with $\mathrm{CH}_{3} \mathrm{NH}_{3} \mathrm{PbBr}_{3}$ single crystals directly grown on vertically aligned carbon nanotube forests as contact electrodes. Under the applied electric field, charged ions in the crystal drift and accumulate in the vicinity of the electrodes, resulting in an in operando formed $\mathrm{p}-\mathrm{i}-\mathrm{n}$ heterojunction. The decreased interface energy barrier and the strong charge injection due to the CNT tip enhanced electric field result in a bright green light emission up to $1800 \mathrm{~cd} /$ $\mathrm{m}^{2}$ at room temperature (average $\approx 60 \mathrm{~cd} / \mathrm{m}^{2}$ ). Beyond the light emission, this original device architecture points to the possibility of implementing vertically aligned CNTs as electrodes in operationally stable perovskite-based optoelectronic devices.

KEYWORDS: Perovskite light emission, room temperature, switchable photovoltaic effect, light-emitting electrochemical cells, vertically aligned carbon nanotubes

$I_{h}^{n}$ $\mathrm{n}$ the past decade semiconducting organic-inorganic lead halide perovskites, such as methylammonium lead triiodide, $\mathrm{CH}_{3} \mathrm{NH}_{3} \mathrm{PbI}_{3}\left(\mathrm{MAPbI}_{3}\right)$, and methylammonium lead tribromide $\mathrm{CH}_{3} \mathrm{NH}_{3} \mathrm{PbBr}_{3}\left(\mathrm{MAPbBr}_{3}\right)$, seem to become one of the most potent game-changers in the photovoltaic industry. ${ }^{1-4}$ Most recently, apart from their use in next generation solar cells, ${ }^{5}$ fast photon detection, even at low illumination intensities, ${ }^{6}$ gas sensing, ${ }^{7}$ promising thermoelectric figure of merit, ${ }^{8,9}$ memristive effects, ${ }^{10}$ optically switched ferromagnetic behavior in magnetic ions doped $\mathrm{MAPbI}_{3}$ single crystals has also been demonstrated. ${ }^{11}$

For solar cells the detailed balance equation requires external luminescence efficiency close to $100 \%$ to attain the ShockleyQueisser limit of $\approx 33.5 \%$, thus, implying that an excellent solar cell material must also be an excellent light emitter. As a result, perovskites have rapidly transitioned from breakthrough materials for solar cells to exceptional semiconducting materials with wide-range of applications in light emission. ${ }^{12}$ High photoluminescence combined with compositional flexibility place perovskites as robust technological candidates distinguished by their high color purity $(\mathrm{fwhm} \approx 20 \mathrm{~nm}){ }^{12}$ bandgap tunability to cover the entire spectrum of visible light, ${ }^{13,14}$ and low-to-moderate ionization energy (IE) to form stable functional interfaces. ${ }^{15}$

Therefore, lead halide perovskites were successfully integrated into light-emitting optoelectronic prototype devices. Tunable amplified spontaneous emission and lasers, ${ }^{16,17}$ light- emitting field effect transistors, ${ }^{18}$ and light-emitting diodes (LEDs) from the infrared ${ }^{19}$ to bright-green range have been demonstrated. $^{20}$ A typical state-of-the-art perovskite LED possesses a complex, multilayer device architecture, which usually consist of: a hole-transport layer, a light-emitting sheet of 3D layered ${ }^{19,20}$ or nanostructured ${ }^{21,22}$ perovskite, an electron-transport layer and electrical contacts. The use of electron- and hole-transport layers is considered to be crucial for perovskite LEDs because it lowers the electron/hole injection energy barriers, resulting in low operation voltage and high electroluminescence (EL) efficiency. ${ }^{23}$ However, fabrication of such devices is more complicated and necessitates utilization of orthogonal solvents and air-sensitive transport layers. Finding alternative material for electrodes is therefore essential for commercial applications of perovskite-based optoelectronic devices.

Here we present a fairly simple architecture for lightemitting device, which consists only of two components, methylammonium lead tribromide (hereafter, $\mathrm{MAPbBr}_{3}$ ) and vertically aligned carbon nanotube (VACNT) forests as contact electrodes. The operational principle is based on ion migration under an electric field. The space charge at the contacts reduces the barrier for charge injection, and the electrons and holes recombine in the crystal, resulting in light

Received: November 29, 2018

Published: March 5, 2019 
a

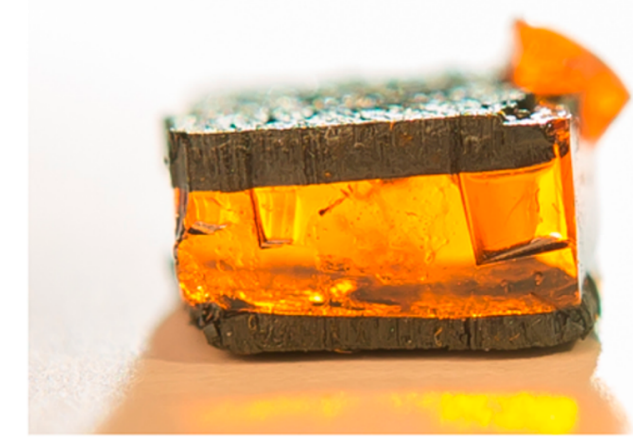

b

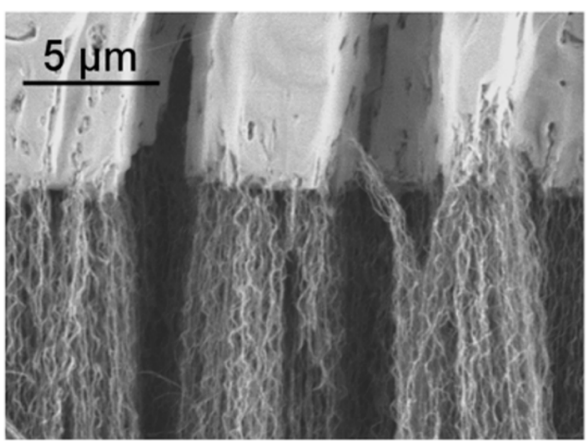

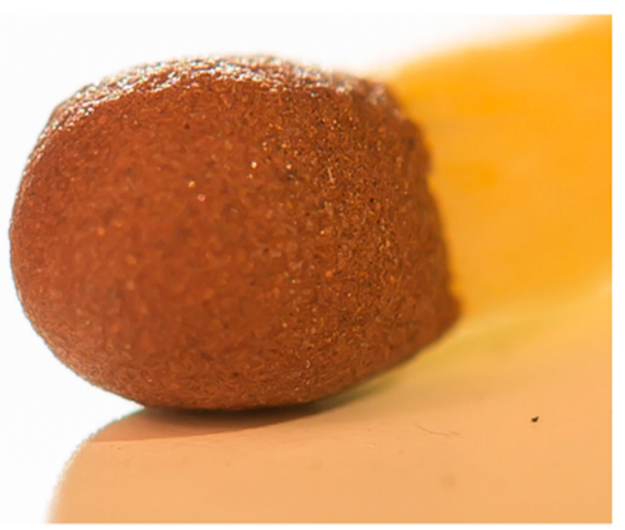

C

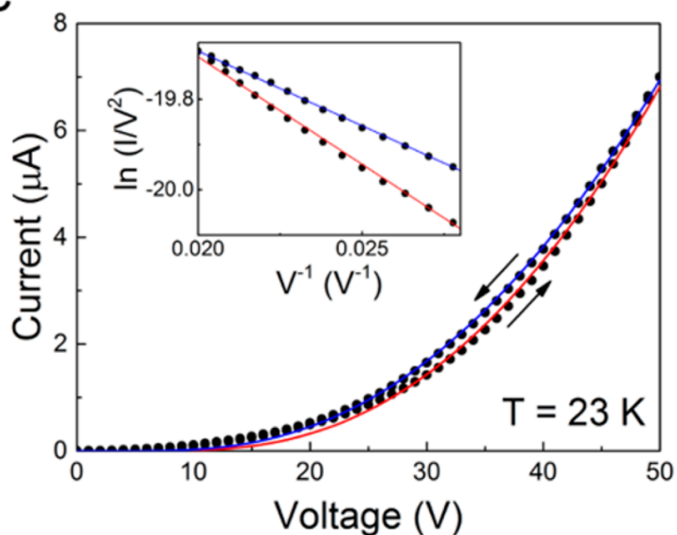

Figure 1. Presentation of the light-emitting electrochemical cell: (a) Optical image of a $\mathrm{MAPbBr}_{3}$ single crystal sandwiched between two VACNT electrodes, resulting in a symmetric architecture (the match gives the scale); (b) SEM image of the interface between $\mathrm{MAPbBr}_{3}$ and the engulfed VACNT electrodes; (c) Current-voltage characteristics of a symmetric device. The inset shows an essential feature of the device: the very efficient charge injection from CNTs by field emission represented by the Fowler-Nordheim plot.

emission. We take advantage of the strong electric field enhancement at the nanotubes tip for increased charge injection (up to $3 \mathrm{~mA}$ ) into the crystal. The basic principle of our device is very similar to the mechanism of light-emitting electrochemical cells (LECs). ${ }^{24-29}$ These light-emitting devices are often very complex, employing a broad range of active ion-conducting layers-from varius types of polymer to, more recently, perovskite/ionic electrolyte composites. In this context, the simple single crystal-based device described herein presents an unprecedented color purity for an LEC (full width at half-maximum of $7 \pm 1 \mathrm{~nm}$ at $20 \mathrm{~K}$ ), and the operation extends to room temperature, achieving an average brightness of $\approx 60 \mathrm{~cd} / \mathrm{m}^{2}(50 \mu \mathrm{A})$ up to flashes of maximum brightness of $1800 \mathrm{~cd} / \mathrm{m}^{2}$ at $2.8 \mathrm{~mA}$. Knowing the ease for growing both $\mathrm{MAPbBr}_{3}$ and $\mathrm{VACNT}$, this result represents a viable route for future light-emitting devices, as well expanding the family of hybrid perovskite LECs.

\section{RESULTS AND DISCUSSION}

Perovskite light-emitting devices were fabricated by immersing VACNT forests into a saturated solution of $\mathrm{MAPbBr}_{3}$. Under the inverse temperature crystal growth conditions, ${ }^{30}$ the fastgrowing single crystal gradually protruded and engulfed the individual carbon nanotubes (CNTs). Elemental analysis by EDX in Figure $S 1$ shows clearly the interfaces and the engulfed, overlapping region between $\mathrm{CNTs}$ and $\mathrm{MAPbBr}$, resulting in a three-dimensionally enlarged $\mathrm{MAPbBr}_{3} / \mathrm{VACNT}$ junction. ${ }^{31}$ Such process, repeated on the opposite side of the perovskite single crystal, allow vertically aligned CNTs to latch also onto this facet, thus forming a symmetric device architecture, with double VACNT electrodes (Figure 1a,b). This is our central device (most of the discussion is addressed to it), but for the sake of comparison, an asymmetric contact device was also prepared with one VACNT and one silver electrode.

An important feature of our device is field emission from VACNTs, since carbon nanotubes are well-known to act as field emitters in vacuum ${ }^{32}$ or in a dielectric, in this case $\mathrm{MAPbBr}_{3}$. Field emission is a charge-injection mechanism occurring when electrons tunnel through a potential barrier under a bias lower than the breakdown voltage. Experimentally, its signature is observed in the $I-V$ measurements, as provided by the empirical Fowler and Nordheim equation: ${ }^{33} I$ $=A V^{2} \exp (-B / V)$, where $A$ and $B$ depend on the geometry and local environment of the field-emitters and on the dimensions of the device. The linear relationship between $\ln \left(I / V^{2}\right)$ and $1 / V$ in the inset of Figure $1 \mathrm{c}$ and in Figure S2 thus support field emission from VACNTs into $\mathrm{MAPbBr}_{3}$, at low and ambient temperatures. Interestingly, the slope (the coefficient $B$ ) in the inset varies with the sweep direction, pointing toward a change of the geometry of the tunneling barrier.

The $I-V$ characteristics for both the symmetric and the asymmetric device architectures were collected under white light illumination. In our previous work it was shown that these 

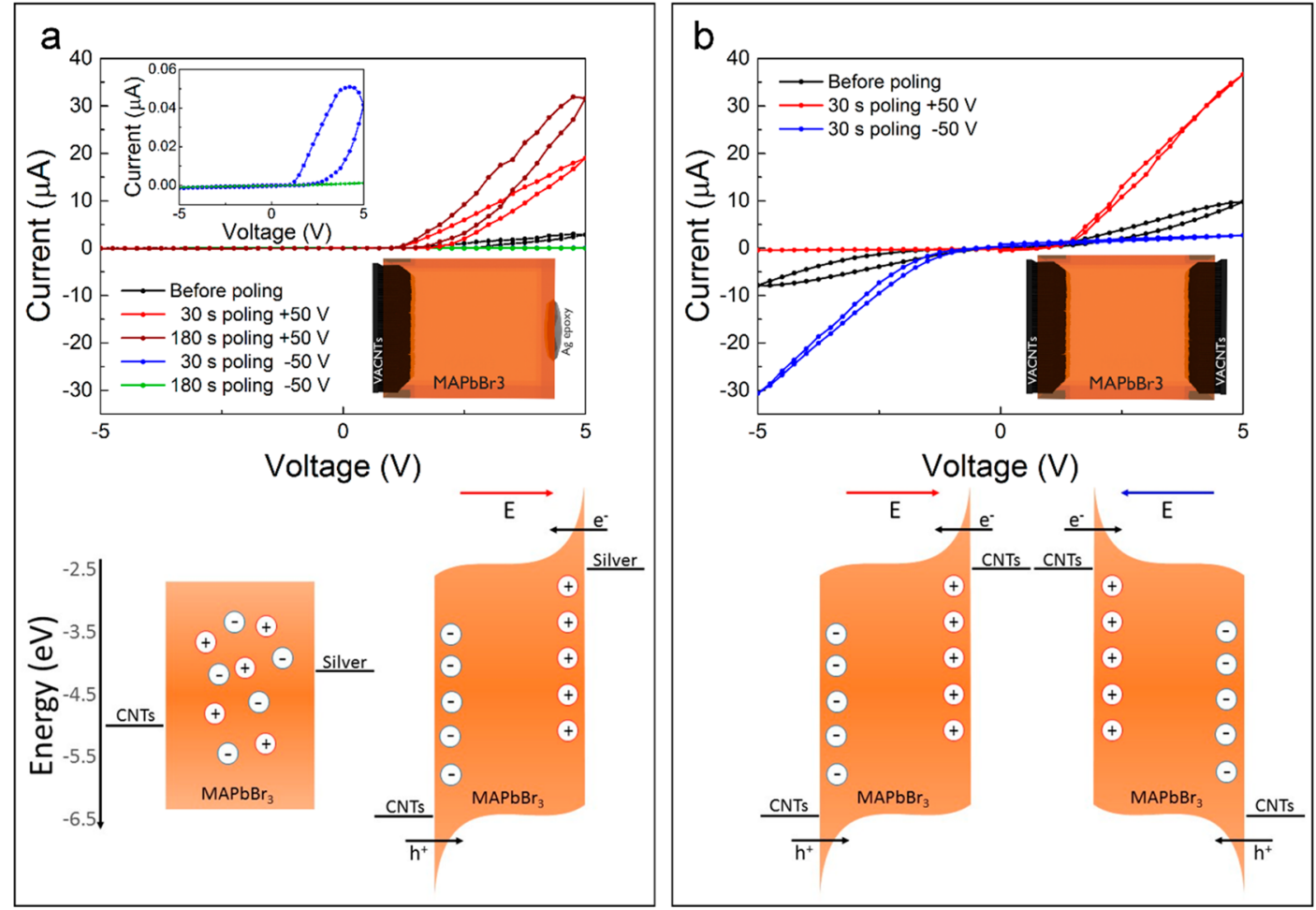

Figure 2. $I-V$ characteristics of the (a) asymmetric device (sketched in the inset) and (b) of the symmetric device (sketched in the inset). The schematic representation of the energy level of the contacts and the position of the ions in open circuit conditions and under an applied external electric field is given below the $I-V$ curves. They were collected under visible light illumination (intensity $1.02 \mathrm{~mW} \mathrm{~cm}^{-2}$ ), before and after poling treatment, with applying different bias voltage polarities. The voltage was swept from 0 to $\pm 5 \mathrm{~V}$ and back. The current intensities through the device attain lower or higher values while increasing or decreasing bias voltage, respectively. Inset (a): Suppression of diode characteristics of the asymmetric device after reverse bias poling.

devices (asymmetric photodiodes) could serve as very sensitive light detectors, capable of detecting low light intensities down to nano-Watts. ${ }^{31}$ One could notice that hysteresis is present in the $I-V$ characteristics and has been associated with the inertia of ion migration in forward and reversed biases.

The characterization is performed by $I-V$ measurements for both types of devices before and after performing voltage preconditioning, called poling, creating space charge regions. ${ }^{10,34}$ As shown in Figure $2 \mathrm{a}, \mathrm{b}$, the $I-V$ characteristics acquired before poling treatment (black) were different for the two types of devices because of the differences in the work functions $(\Phi)$ of silver and CNTs. Silver has a $\Phi$ of $4.2 \mathrm{eV},{ }^{35}$ whereas that of CNTs is $5.05 \mathrm{eV}^{36}$ Therefore, it is expected that the asymmetric $\mathrm{Ag} / \mathrm{MAPbBr}_{3} / \mathrm{VACNT}$ device (Figure 2a) has diode-like characteristics, allowing current to flow in the forward bias direction while suppressing the flow at reversed polarity due to the high Schottky barrier. After a constant bias voltage is applied for a short period of $30 \mathrm{~s}$, the $I-V$ scans performed at rate of $2 \mathrm{~V} \mathrm{~s}^{-1}$ are different from those before poling. When the device is poled under forward bias, the diode characteristics are preserved, with an increase of current from 2 $\mu \mathrm{A}$ to $32 \mu \mathrm{A}$ at $5 \mathrm{~V}$ (red). Interestingly, when a constant bias voltage of opposite polarity is applied, the diode characteristics are suppressed (blue) and even nullified (green) in the applied field range (from $2 \mu \mathrm{A}$ falls to $2 \mathrm{nA}$ at $5 \mathrm{~V}$ ), obtaining symmetric $I-V$ characteristics after $180 \mathrm{~s}$ of poling (inset Figure 2a).

The modification of the $I-V$ characteristics is even more pronounced for the device with two VACNT electrodes (Figure 2b). Having symmetrical junctions, it has Schottky I-
$V$ characteristics for both positive and negative bias voltages. However, if a constant bias voltage is applied for $30 \mathrm{~s}$ just before a quick voltage sweep $\left(2 \mathrm{~V} \mathrm{~s}^{-1}\right)$, the $I-V$ characteristics completely change to a typical diode-like behavior. Now, current flows for voltages of the polarity of the previously applied bias. These changes as well as the time of relaxation back to the initial states depend on the time of voltage preconditioning and on the value of the bias voltage. The effects of poling in detail, as well as the changes of $I-V$ characteristic under different times of poling (10 s to $10 \mathrm{~min}$ ) and poling voltages $(1-200 \mathrm{~V})$ are shown in Figure S3. Moreover, it is possible to change the polarity of the open circuit voltage, as seen in Figure S3e,f, achieving a switchable photovoltaic effect. ${ }^{10}$

In open-circuit conditions, ions of opposite signs are uniformly distributed within the active layer (Figure 2a). After a constant bias voltage is applied, the ions drift toward their respective electrodes and they accumulate at the perovskite/metal interface forming $\mathrm{p}-\mathrm{i}-\mathrm{n}$ heterojunction structures, increasing the injection rate of electrons and holes from the electrodes to the perovskite layer and governing the devices $I-V$ characteristics (Figure 2b). It is worth to mention that hysteresis was observed in perovskite solar cells, as well, attributing it to ion migration inside the perovskite layer. ${ }^{37-40}$

At bias voltages $\left(V_{\mathrm{b}}\right)$ larger than $5 \mathrm{~V}$, the current through the device increased over 3 orders of magnitude (from nA to $\mu \mathrm{A}$ ) before saturating. Remarkably, at ambient conditions and starting from the current intensities through the device of $~ 50$ $\mu \mathrm{A}$, a bright green EL was first observed for the asymmetric device (Figure S4a). Voltages much larger than the band gap 
were used to achieve this critical current for light emission. Nevertheless, due to the large thickness of our single crystal devices $(>1 \mathrm{~mm})$, the external electric field was never larger than $200 \mathrm{~V} \mathrm{~mm}^{-1}$.

To achieve light emission for both polarities, the focus had been moved to the symmetrical device architecture employing VACNTs as both electrodes on the perovskite single crystal. The device, previously conditioned to show diode-like behavior, exhibit light emission with further poling at room temperature in ambient conditions. For this device architecture, light emission is visible for both polarities, as shown on Figure S4b. Interestingly, the depletion region, which arises due to the high electric field $\left(\sim 10 \mathrm{~V} \mathrm{~mm}^{-1}\right)$, which is the region where the bright light emission is observed, is always near the interface with the lower potential, as was the case for the asymmetric device.

Bright green light is emitted at room temperature in the form of repetitive flashes of $100-120 \mathrm{~Hz}$. In $20 \mathrm{~s}$ of acquiring light intensity and simultaneously measuring the current through the device, more than 40 excitations can be visible from multiple locations near the active surface of the device (Figure 3a). This yields an average luminance of $\sim 60 \mathrm{~cd} / \mathrm{m}^{2}$ for current as low as $50 \mu \mathrm{A}$. At higher currents, more charges are injected into the single crystal, resulting in brighter (max. $1800 \mathrm{~cd} / \mathrm{m}^{2}$ for $2.8 \mathrm{~mA}$ current) and more frequent flashes (Figure $3 \mathrm{~b}$ ). Importantly, stable and continuous light emission has not been observed at ambient conditions. It is likely that the space charge created by the migrated ions in electric field is exposed to thermal fluctuations. The fluctuations change the barrier structure in time, resulting in a fluctuating injected current and light intensity. Current instability at a constant voltage has been common for MWCNT field emitters. ${ }^{32}$ However, these emitters observe switching between discrete current levels at low currents, reaching more stable emission at higher currents, whereas the perovskite light-emitting device exhibits random fluctuations, increasing with the value of current. Nevertheless, this is still an open question and should be taken into further consideration.

These fluctuations are damped by cooling the system down to cryogenic temperatures, because the mobility of ions is strongly reduced. The intensity of the injected current became stable, producing a continuous light emission. For example, at $25 \mathrm{~K}$ a very bright light emission was observed as seen in the inset of Figure 3c. Luminance-current versus applied voltage (LIV) of the symmetric LEC device for both negative and positive voltages is shown in Figures $3 \mathrm{c}$ and S5, respectively. Since the light emission comes from the recombination of electrons and holes in the perovskite, it is expected that the EL intensity correlates with the injected current in $\mathrm{MAPbBr}_{3}$. This is fully confirmed by the LIV measurements at $25 \mathrm{~K}$ as well as their dependence with temperature (Figure S5). Continuous light emission stopped at $100 \mathrm{~K}$, but flashes of light with quick changes of intensities could be followed up to room temperature. The device showed stable light emission for up to $1 \mathrm{~h}$ operation (Figure S5f). The light emission at room temperature, in the form of flashes, and at low temperatures, as a constant light in the dependence of voltage, can be seen in the video in the Supporting Information.

The spectral analysis of the emitted light at $20 \mathrm{~K}$ was performed for turn-on voltages in the range of 100 to $200 \mathrm{~V}$ and -30 to $-40 \mathrm{~V}$. The different colors of the emitted light for the two cases are already visible with the naked eye (see inset to Figure 4). Two sets of spectra with similar intensity count
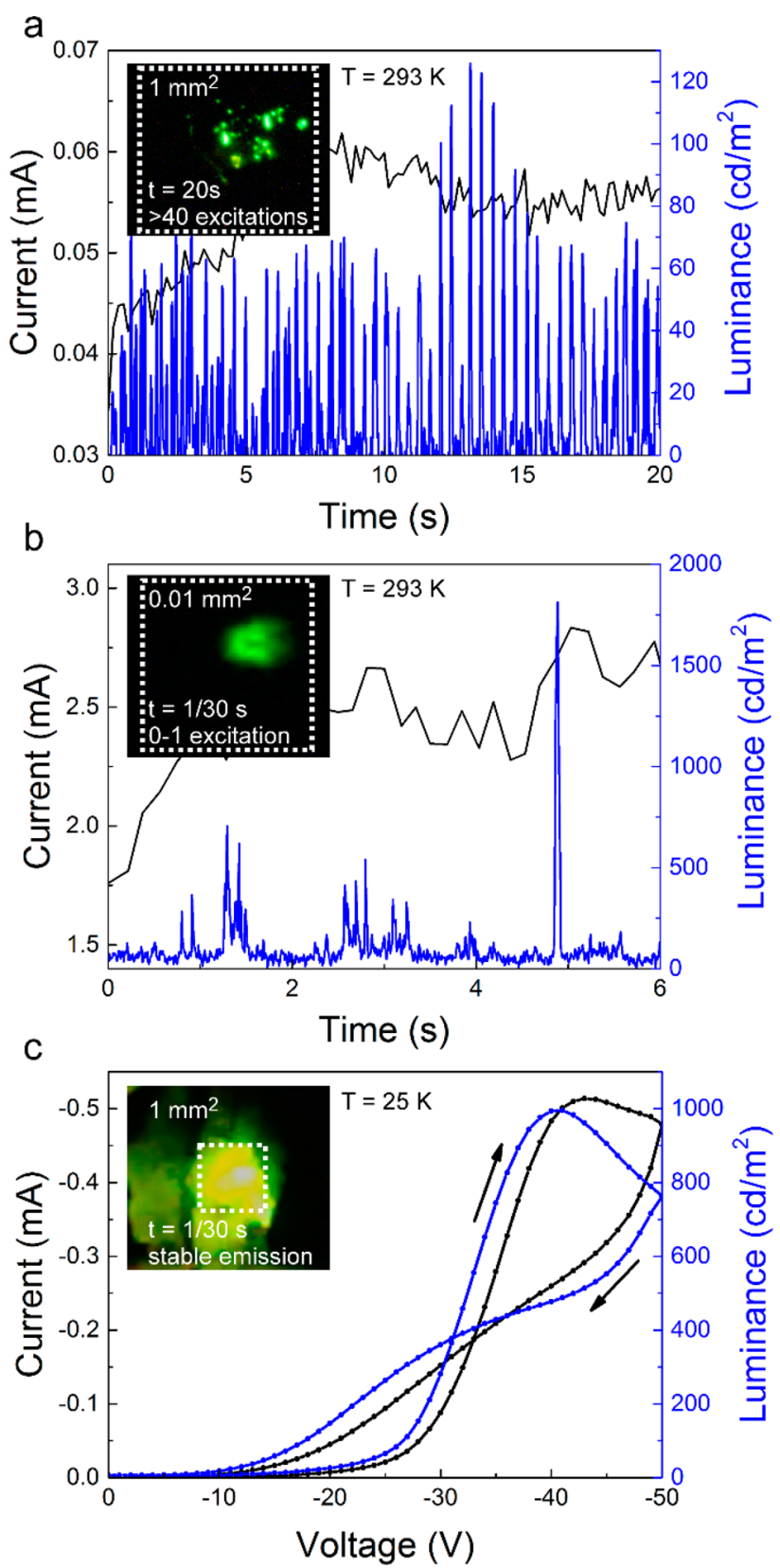

Figure 3. (a) Luminance-current in time for an applied bias voltage of $20 \mathrm{~V}$ at room temperature. Inset: Optical image of $>40$ flashes of light of light during $20 \mathrm{~s}$ at room temperature. (b) Luminancecurrent in time for an applied voltage of $40 \mathrm{~V}(>2 \mathrm{~mA}$ current $)$ at room temperature. Inset: Screen shot of a video of the light emission at room temperature showing the emitting surface of less than 250 $\mu \mathrm{m}^{2}$. (c) Luminance-current vs voltage at cryogenic temperatures $(25 \mathrm{~K})$. Inset: Screen shot of a video of the light emission showing stable light emission with an active emitting surface of $1 \mathrm{~mm}^{2}$.

numbers were chosen of both polarities and fitted with a Gaussian function (Figure 4). One can read from these spectra two important information: (i) the redshift by $20 \mathrm{~nm}$ of the negative bias spectra compared to the spectra acquired for positive voltages; and (ii) the very narrow full width at halfmaximum (fwhm), of the order of $8 \mathrm{~nm}$, which represents a high spectral purity. This latter fact is certainly due to the high crystallinity of the sample. In polycrystalline sample or in polymer LECs the spectra are broader multiple times due to the inherent disorder. ${ }^{41}$ When applying $150 \mathrm{~V}$, bright green 


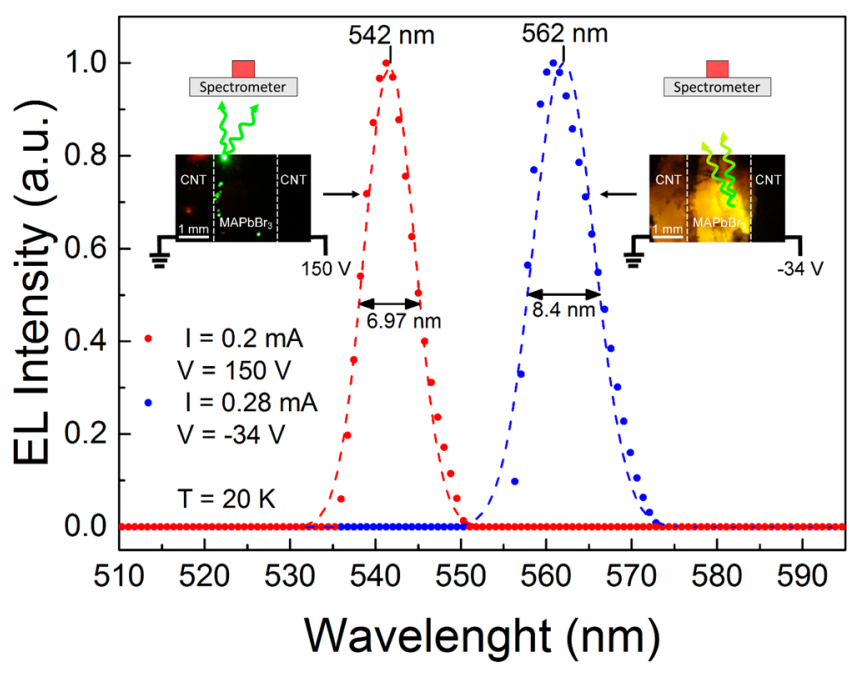

Figure 4. Typical normalized EL spectra recorded at $20 \mathrm{~K}$ in vacuum, at positive $(\mathrm{red},+150 \mathrm{~V})$ and negative (blue, $-34 \mathrm{~V}$ ) bias voltages, fitted with Gaussian function (dashed lines). Inset: Schematic illustration of the measurement setup with the photos of the light emission for the associated EL spectra.

spots with an emission peak centered at $542 \mathrm{~nm}$ wavelengths have the energy of the band gap. The $-40 \mathrm{~V}$ biased case gives a red-shifted signal at $562 \mathrm{~nm}$. It is likely that the different colors are due to different locations of recombination of the electron-hole pairs in the crystal. Our conjecture is that the green light is coming mostly from the crystal surface, while the yellowish light is from the bulk. Deep in the crystal, after recombination, the light is absorbed and re-emitted in cascades before reaching the spectrometer, and during this process, the slight energy loss results in a redshift of the spectra. On the other hand, for positive voltages, the recombination takes place near the surface, the light is directly emitted toward the spectrometer at a wavelength of $542 \mathrm{~nm} .{ }^{30}$ Similar arguments were put forward for red-shifted spectra in photoluminescence measurements by Wenger et al. ${ }^{42}$ All the acquired EL spectra with their associated currents are given in Figure S6.

In order to obtain a more complete picture, about the limiting factors of the EL phenomenon in the symmetric architecture, light emission were collected with increasing temperatures from 23 to $40 \mathrm{~K}$ for the $-40 \mathrm{~V}$ biased case (Figure 5a), and spectral analysis was performed (Figure 5b). At $23 \mathrm{~K}$, two EL emission peaks were detected: one at $562 \mathrm{~nm}$ with a fwhm of about $7 \mathrm{~nm}$, which is the same as in Figure 4, and a second broad peak at $590 \mathrm{~nm}$ with a fwhm of $10 \mathrm{~nm}$. With increasing temperature, the intensity of the peak located at $562 \mathrm{~nm}$ weakens with no significant shift in wavelength and fwhm, while the peak centered at $590 \mathrm{~nm}$ increases in intensity, simultaneously undergoing a redshift and broadening, achieving a fwhm of $30 \mathrm{~nm}$ at $40 \mathrm{~K}$ (Figure 5c). We suspect that this peak emerges from radiative recombination at trap states in the perovskite single crystal. The increasing intensity with temperature corroborates with this attribution, as the population of these trap-states grows with temperature. With a further increase in temperature, higher absolute values of bias voltages and longer spectrometer integration times were needed to acquire spectra curves. This was possible only for the second peak at $590 \mathrm{~nm}$ up to $60 \mathrm{~K}$, as shown in Figure S7. The redshift and the increasing fwhm is coming from the interaction of the created photons with lattice vibrations.
These features are confirmed on the asymmetric device recorded in the 40-300 K range shown in Figures S8 and S9.

In the above documented EL, the poling, which is the movement of ions under an electric field, is primordial (like in polymeric LECs), and the building up of the space charge layer near the contacts facilitate the charge injection into the crystal. To have a better insight into the time scale of this phenomenon, we have studied the time-dependence of the current increase upon applying a constant external voltage of $10 \mathrm{~V}$ during $10 \mathrm{~h}$ (Figure S10). The monotonic increase of current was fit by a triexponential function, giving three time constants. The shortest one (65 s) corresponds to the halogen ion movement, the intermediate $(35 \mathrm{~min})$ to the MA+ diffusion, and the longest one $(7 \mathrm{~h})$ to the slow thickening of the space charge layer. Such a hierarchy of the diffusion activation energies was found by Puscher et al. ${ }^{43}$ as well. It has to be mentioned that no detectable degradation of the device was observed during the 10 working hours of operation at ambient atmosphere.

A further characterization of the device is done by measuring its capacitance $(C)$ via the discharge current (similarly to Zhang et al. ${ }^{44}$ ) after poling of the VACNT/MAPbBr 3 / VACNT sample (thickness $1 \mathrm{~mm}$, surface area $10 \mathrm{~mm}^{2}$ ). A certain bias (e.g., $2 \mathrm{~V}$ ) was applied for a short period of time $(\approx 15 \mathrm{~s})$ in the dark to accumulate the ions at the perovskite/ CNT interfaces, that is to charge the $C_{i}$, which represents the areal capacitance from the blocking of ions at the electrode interfaces. ${ }^{38}$ The device was then rapidly switched to zero bias to measure the discharge current (Figure S11a, inset). The accumulated charge density is the time integral of the discharge current normalized to the perovskite electrode interface. From the measured charge densities of the accumulated ions at the interfaces under various biases (Figure S11a), one can extract a value of $C_{\mathrm{i}} \approx 1 \mu \mathrm{F} \mathrm{cm} \mathrm{cm}^{-2}$. This large areal capacitance exceeds that of conventional electrostatic capacitors, ${ }^{45}$ with a typical value of $0.1 \mu \mathrm{F} \mathrm{cm}^{-2}$. Furthermore, as shown in Figure S11b, the areal capacitance increases with the poling time. These results suggest that the organic-inorganic perovskites could serve as potential solid-state supercapacitors.

In general, the light-emitting electrochemical device are becoming increasingly popular and implement a broad range of active layers that possess the ionic conductivity. ${ }^{24}$ Mostly, these are conjugated polymers, ionic transition-metal complexes, small molecules, and quantum dots, to recently used perovskite nanoparticles. ${ }^{46}$ The latter one was used by Aygüler and co-workers, using $\mathrm{MAPbBr}_{3}$ and $\mathrm{FAPbBr}_{3}$ perovskites mixed with an ion polyelectrolyte (IP) to increase the ionic conductivity. ${ }^{47}$ Following up this contribution, light emission was achieved in mixtures of perovskite nanoparticles with poly(ethylene oxide) (PEO) polymers, ${ }^{41}$ composite films, ${ }^{48}$ or as thin films using ITO/PEDOT:PSS and $\mathrm{MoO}_{3} / \mathrm{Au}$ electrodes. For the sake of completeness, the best-in-class perovskitebased LECs and LEDs are shown in Table S2.

\section{CONCLUSION}

Here we demonstrated the operation of new, simple LECs based on $\mathrm{MAPbBr}_{3}$ and VACNTs. Our VACNT/MAPbBr $/$ / VACNT device is the first room-temperature, single-crystal light emitter using symmetrical metallic electrodes without electrolyte or additional $n$ - or p-type selective layers. Due to the single crystalline nature of the active material, the spectral purity of the emitted light is very high at low temperatures. The oriented carbon nanotubes by field emission inject a high 
a

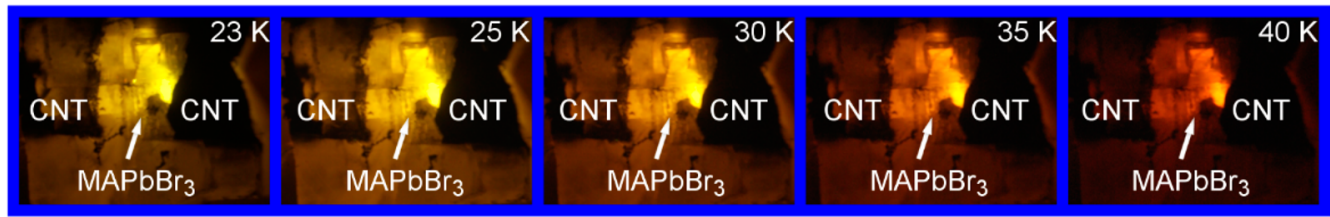

b

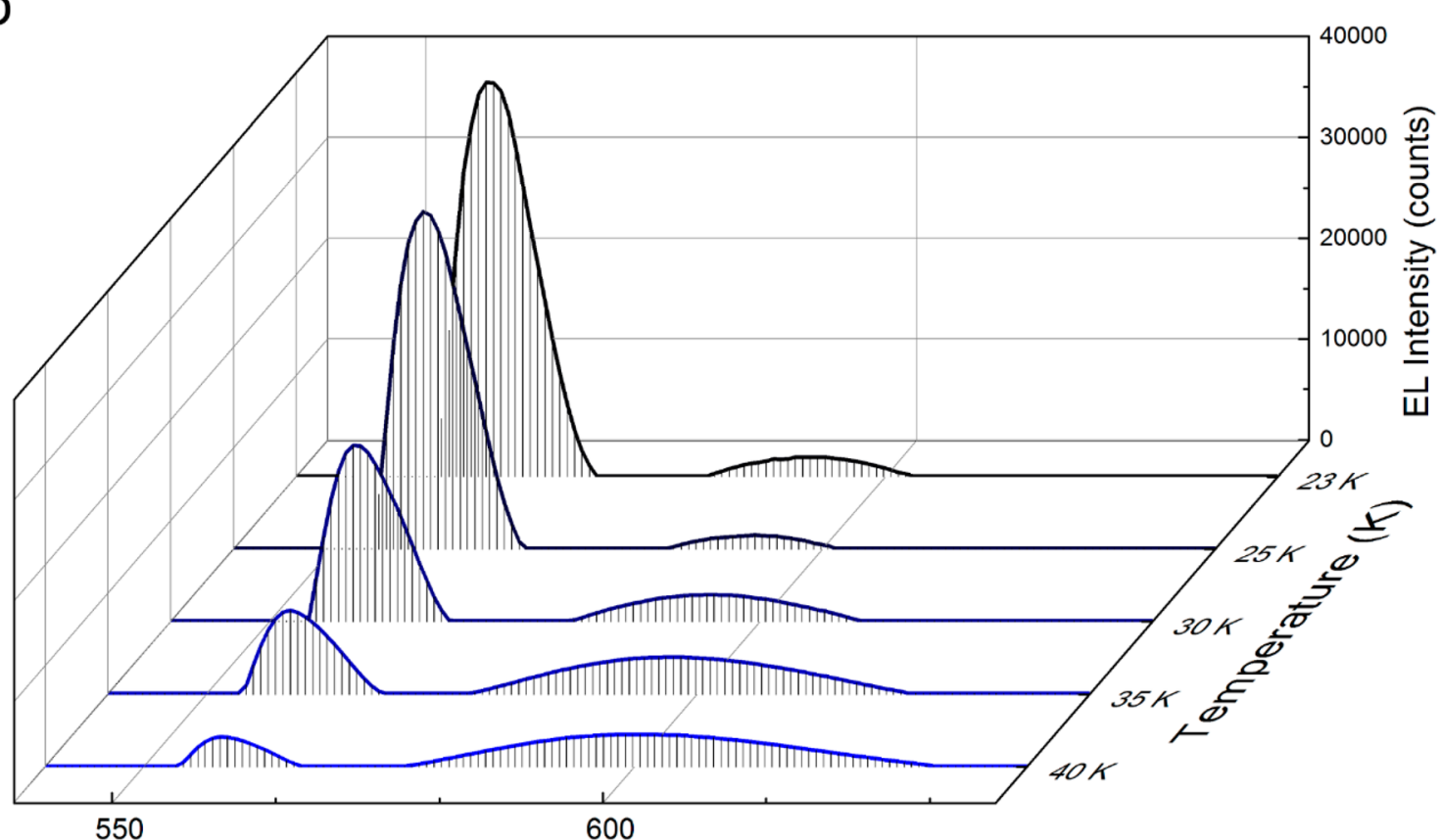

C

Wavelength $(\mathrm{nm})$

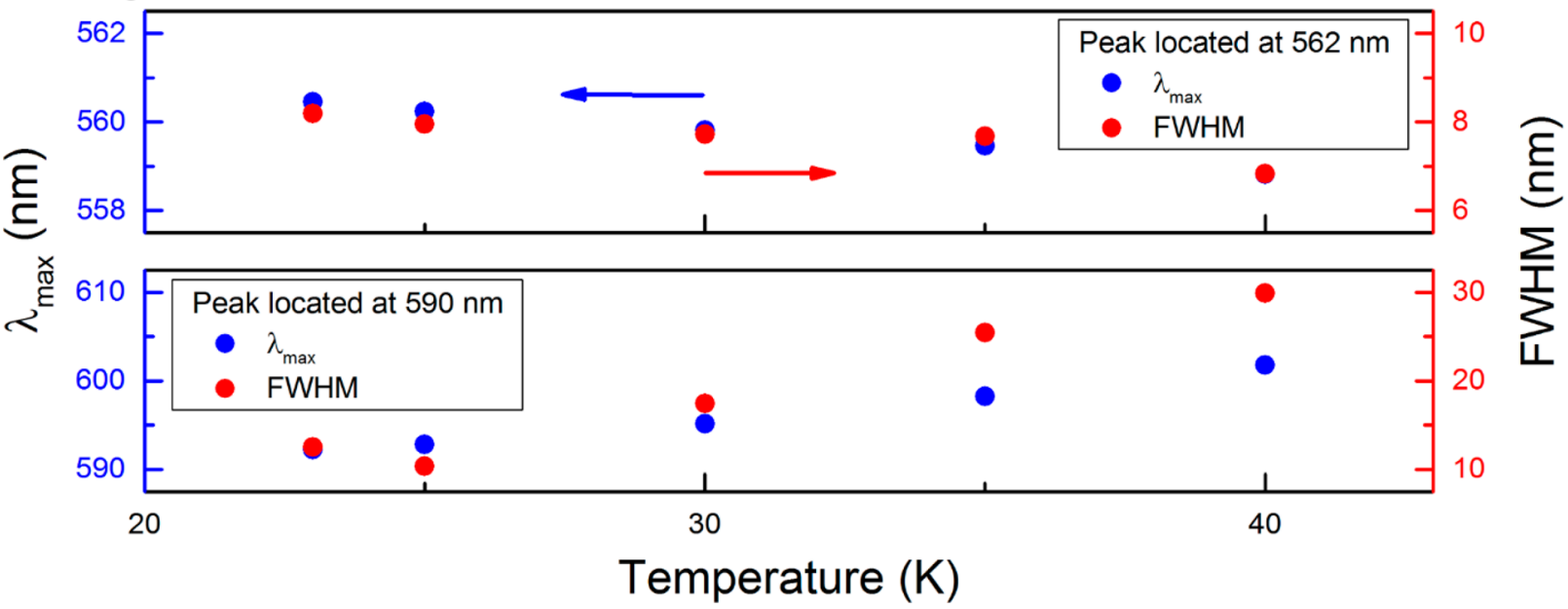

Figure 5. (a) Optical images of the light emission with $-40 \mathrm{~V}$ of bias voltage as a function of temperature, highlighting the redshift. (b) Spectral analysis of the EL spectra reveal an emission peak at 562 and $592 \mathrm{~nm}$ at $23 \mathrm{~K}$, which have different temperature dependences. (c) The temperature dependence of the wavelength and fwhm extracted from a Gaussian fit.

current density (due to the tip-enhanced electric field), which gives bright light emission up to $1800 \mathrm{~cd} / \mathrm{m}^{2}$, even at room temperature. The design developed herein points to the possibility of implementing vertically aligned CNTs as electrodes in operationally stable optoelectronic devices. The VACNT-based technology can also serve as a versatile platform for future electrode development.

\section{EXPERIMENTAL SECTION}

VACNT Growth. Carbon nanotubes were grown by catalytic chemical vapor deposition. First, transition metals, such as $\mathrm{Fe}, \mathrm{Co}, \mathrm{Ni}$, or their alloys were used as the catalysts, while $\mathrm{Al}_{2} \mathrm{O}_{3}, \mathrm{MgO}$, and $\mathrm{SiO}_{2}$ as oxide supports. VACNT are then grown utilizing a special preparation protocol documented in our previous work ${ }^{31,49,50}$ named the supergrowth method. The CNT self-assemble into vertically oriented cellular arrays during the growth on the substrate as high as $2.5 \mathrm{~mm}$. The VACNT forest contain predominantly multiwall 
CNTs and are $95 \%$ porous allowing the direct grow of perovskite SC on the VACNT forest.

Crystal Growth. Crystals of the methylammonium lead tribromide were synthesized by solution growth. The lead(II) acetate trihidrate $\left(3.3 \mathrm{mmol}, \mathrm{Pb}(\mathrm{ac})_{2} \cdot 3 \mathrm{H}_{2} \mathrm{O},>99.9 \%\right)$ was reacted with saturated $\mathrm{HBr}$ solution $(6 \mathrm{~mL}, 48 \mathrm{wt} \% \mathrm{HBr}$ in $\mathrm{H}_{2} \mathrm{O}$ ). The formed $\mathrm{PbBr}_{2}$ precipitate is stable in the acidic solution. The respective amount $(3.30 \mathrm{mmol})$ of methylamine $\left(\mathrm{CH}_{3} \mathrm{NH}_{2}\right)$ solution $\left(40 \mathrm{wt} \%\right.$ in $\left.\mathrm{H}_{2} \mathrm{O}\right)$ was pipetted into the 5 ${ }^{\circ} \mathrm{C}$ ice cooled solution of $\mathrm{PbBr}_{2}$. The cold solution avoids the evaporation of methylamine during the exothermic reaction. Orange colored microcrystallites of $\mathrm{CH}_{3} \mathrm{NH}_{3} \mathrm{PbBr}_{3}$ were formed. The $\mathrm{MAPbBr}_{3}$ crystals were recrystallized in a temperature gradient of $15{ }^{\circ} \mathrm{C}$ in the acidic media to get transparent, high purity crystals.

$\mathrm{MAPbBr}_{3}$ single crystals were grown by inverse temperature crystallization from its saturated solution in DMF. $\mathrm{MAPbBr}_{3}$ $(0.8 \mathrm{~g})$ was dissolved per $\mathrm{cm}^{3}$ of DMF at room temperature. The substrate was immersed in the solution, and a $\mathrm{MAPbBr}_{3}$ seed crystal was placed on the top of the VACNT. Crystal growth was initialized by increasing the temperature of the solution from room temperature to $40{ }^{\circ} \mathrm{C}$ with a heating rate of $5{ }^{\circ} \mathrm{C}$ per hour. We observed that the fast-growing seed single crystals gradually protruded and engulfed the individual nanotubes. These types of inclusions, when the original form of the included mineral is preserved in the host crystal is categorized as a protogenetic inclusion in mineralogy. The slow heating rate suppress the formation of new seed crystals in the supersaturated solution and our $\mathrm{MAPbBr}_{3}$ seed crystal can grow rapidly on the substrate. When the required size of crystal was reached, the $\mathrm{MAPbBr}_{3}-\mathrm{VACNT}$ composite was removed from the solution, wiped, and dried. The same growth method was repeated using the $\mathrm{MAPbBr}_{3}-\mathrm{VACNT}$ junction as a seed crystal to obtain two VACNT electrodes on the perovskite single crystal.

Optoelectronic Characterization. All measurements of the $I-V$ characteristics of the device and dependence to poling at room temperature were done in ambient conditions. The device characteristics have been determined by two-point resistivity measurements, using golden wires contacted with Dupont 4929 silver epoxy as electrical leads. A Keithley 2400 source meter allowed us to measure the current with $<0.1 \mathrm{nA}$ resolution while tuning the applied bias voltage, in the dark and under visible light illumination.

Intensity Measurements of the Light Emission at Room Temperature. A Thorlabs PM100D Compact Power and Energy Meter Console with its corresponding software were used to obtain the intensities of light with $<0.1 \mathrm{nW}$ resolution. The light-emitting device was contacted with two tungsten needles as electrical leads. A Keithley 2400 source meter was use to apply voltage to the sample and measure current with $<0.1 \mathrm{nA}$ resolution. The photodetector was positioned $1 \mathrm{~cm}$ from the sample at a small angle to simultaneously capture optical images or videos of the bright green light with a Canon EOS 600D camera (ISO1600). All measurements were done at room temperature and in an ambient atmosphere.

Intensity and Spectra Measurements of the Light Emission at Low Temperatures. To achieve stable light emission, the light device was mounted inside a close cycle cryostat with optical windows and brought to cryogenic temperatures $(20$ to $80 \mathrm{~K}$ ) and high vacuum. A Keithley 2400 source meter was again used to apply voltage to the sample and measure current with $<0.1 \mathrm{nA}$ resolution. The dependence of the light intensity with voltage and in time were determined by measuring the photocurrent of a Thorlabs FDS100 silicon photodiode, which was positioned $\sim 5 \mathrm{~cm}$ from the sample behind an optical window. Likewise, the spectra of the emitted light were measured using an Ocean Optics QE65 Pro spectrometer. The light was collected using a series of lenses to an optical fiber, positioned on the cryostat optical windows. The spectra were acquired using the Ocean Optics SpectraSuite software. Care was taken to limit the current (max. $2 \mathrm{~mA})$. With increasing temperatures, the absolute value of the voltage had to be adjusted (increased) in order to keep a sufficient current, required for light emission. Luminance of the device was calculated from the spectra at room and cryogenic temperatures, as shown in Figure S12. Due to many losses in our setup (optical windows, etc.) much lower values are obtained compared to direct measurements of intensities of the same device at room temperature. Optical images clearly show a much brighter light, so the intensities obtained by the silicon photodiode are calibrated as shown in the Supporting Information.

\section{ASSOCIATED CONTENT}

\section{S Supporting Information}

The Supporting Information is available free of charge on the ACS Publications website at DOI: 10.1021/acsphotonics.8b01653.

$I-V$ characteristics of the light-emitting device under different pooling schemes, as well as room to cryogenic temperature characterization of the asymmetric LEC device (PDF)

Video: The light emission at room temperature, in the form of flashes, and at low temperatures, as a constant light in the dependence of voltage (AVI)

\section{AUTHOR INFORMATION}

\section{Corresponding Authors}

*E-mail: laszlo.forro@epfl.ch.

*E-mail: endre.horvath@epfl.ch.

ORCID ${ }^{\circ}$

Bálint Náfrádi: 0000-0001-9543-2970

Andrzej Sienkiewicz: 0000-0003-3527-7379

Endre Horváth: 0000-0001-7562-2267

\section{Notes}

The authors declare no competing financial interest.

\section{ACKNOWLEDGMENTS}

This work was supported by the Swiss National Science Foundation (No. 513733) and the ERC Advanced Grant "PICOPROP" (Grant No. 670918). The authors gratefully acknowledge Dr. Daniel Oberli for the technical support in obtaining the light intensity.

\section{REFERENCES}

(1) Lee, M. M.; Teuscher, J.; Miyasaka, T.; Murakami, T. N.; Snaith, H. J. Efficient hybrid solar cells based on meso-superstructured organometal halide perovskites. Science 2012, 338, 643-647.

(2) Kim, H.-S.; Lee, C.-R.; Im, J.-H.; Lee, K.-B.; Moehl, T.; Marchioro, A.; Moon, S.-J.; Humphry-Baker, R.; Yum, J.-H.; Moser, J. E.; et al. Lead Iodide Perovskite Sensitized All-Solid-State Submicron Thin Film Mesoscopic Solar Cell with Efficiency Exceeding 9\%. Sci. Rep. 2012, 2 (1), 591. 
(3) Liu, M.; Johnston, M. B.; Snaith, H. J. Efficient Planar Heterojunction Perovskite Solar Cells by Vapour Deposition. Nature 2013, 501 (7467), 395-398.

(4) Burschka, J.; Pellet, N.; Moon, S.-J.; Humphry-Baker, R.; Gao, P.; Nazeeruddin, M. K.; Grätzel, M. Sequential Deposition as a Route to High-Performance Perovskite-Sensitized Solar Cells. Nature 2013, 499 (7458), 316-320.

(5) NREL Efficiency Chart. https://www.nrel.gov/pv/assets/pdfs/ pv-efficiencies-07-17-2018.pdf (accessed November 14, 2018).

(6) Spina, M.; Lehmann, M.; Náfrádi, B.; Bernard, L.; Bonvin, E.; Gaál, R.; Magrez, A.; Forrõ, L.; Horváth, E. Microengineered $\mathrm{CH}_{3} \mathrm{NH}_{3} \mathrm{PbI}_{3}$ Nanowire/Graphene Phototransistor for Low-Intensity Light Detection at Room Temperature. Small 2015, 11 (37), 48244828.

(7) Bao, C.; Yang, J.; Zhu, W.; Zhou, X.; Gao, H.; Li, F.; Fu, G.; Yu, T.; Zou, Z. A Resistance Change Effect in Perovskite $\mathrm{CH}_{3} \mathrm{NH}_{3} \mathrm{PbI}_{3}$ Films Induced by Ammonia. Chem. Commun. 2015, 51 (84), 1542615429.

(8) Mettan, X.; Pisoni, R.; Matus, P.; Pisoni, A.; Jacimovic, J.; Náfrádi, B.; Spina, M.; Pavuna, D.; Forró, L.; Horváth, E. Tuning of the Thermoelectric Figure of Merit of $\mathrm{CH}_{3} \mathrm{NH}_{3} \mathrm{MI}_{3}(\mathrm{M}=\mathrm{Pb}, \mathrm{Sn})$ Photovoltaic Perovskites. J. Phys. Chem. C 2015, 119 (21), 11506.

(9) Pisoni, A.; Jaćimović, J.; Barišićc, O. S.; Spina, M.; Gaál, R.; Forró, L.; Horváth, E. Ultra-Low Thermal Conductivity in OrganicInorganic Hybrid Perovskite $\mathrm{CH}_{3} \mathrm{NH}_{3} \mathrm{PbI}_{3}$. J. Phys. Chem. Lett. 2014, 5 (14), 2488-2492.

(10) Xiao, Z.; Yuan, Y.; Shao, Y.; Wang, Q.; Dong, Q.; Bi, C.; Sharma, P.; Gruverman, A.; Huang, J. Giant Switchable Photovoltaic Effect in Organometal Trihalide Perovskite Devices. Nat. Mater. 2015, 14 (2), 193-198.

(11) Náfrádi, B.; Szirmai, P.; Spina, M.; Lee, H.; Yazyev, O. V.; Arakcheeva, A.; Chernyshov, D.; Gibert, M.; Forró, L.; Horváth, E. Optically Switched Magnetism in Photovoltaic Perovskite $\mathrm{CH}_{3} \mathrm{NH}_{3}(\mathrm{Mn}: \mathrm{Pb}) \mathrm{I}_{3}$. Nat. Commun. 2016, 7, 13406.

(12) Veldhuis, S. A.; Boix, P. P.; Yantara, N.; Li, M.; Sum, T. C.; Mathews, N.; Mhaisalkar, S. G. Perovskite Materials for LightEmitting Diodes and Lasers. Adv. Mater. 2016, 28, 6804-6834.

(13) Eperon, G. E.; Stranks, S. D.; Menelaou, C.; Johnston, M. B.; Herz, L. M.; Snaith, H. J. Supplementary Information Formamidinium of Formamidinium Lead Trihalide: A Broadly Tunable Perovskite for Efficient Planar Heterojunction Solar Cells. Energy Environ. Sci. 2014, 7 (3), 982.

(14) Nedelcu, G.; Protesescu, L.; Yakunin, S.; Bodnarchuk, M. I.; Grotevent, M. J.; Kovalenko, M. V. Fast Anion-Exchange in Highly Luminescent Nanocrystals of Cesium Lead Halide Perovskites $\left(\mathrm{CsPbX}_{3}, \mathrm{X}=\mathrm{Cl}, \mathrm{Br}, \mathrm{I}\right)$. Nano Lett. 2015, 15 (8), 5635-5640.

(15) Kulbak, M.; Cahen, D.; Hodes, G. How Important Is the Organic Part of Lead Halide Perovskite Photovoltaic Cells? Efficient $\mathrm{CsPbBr}_{3}$ Cells. J. Phys. Chem. Lett. 2015, 6 (13), 2452-2456.

(16) Xing, G.; Mathews, N.; Lim, S. S.; Yantara, N.; Liu, X.; Sabba, D.; Grätzel, M.; Mhaisalkar, S.; Sum, T. C. Low-Temperature Solution-Processed Wavelength-Tunable Perovskites for Lasing. Nat. Mater. 2014, 13 (5), 476-480.

(17) Zhu, H.; Fu, Y.; Meng, F.; Wu, X.; Gong, Z.; Ding, Q.; Gustafsson, M. V.; Trinh, M. T.; Jin, S.; Zhu, X.-Y. Lead Halide Perovskite Nanowire Lasers with Low Lasing Thresholds and High Quality Factors. Nat. Mater. 2015, 14 (6), 636-642.

(18) Chin, X. Y.; Cortecchia, D.; Yin, J.; Bruno, A.; Soci, C. Lead Iodide Perovskite Light-Emitting Field-Effect Transistor. Nat. Commun. 2015, 6 (1), 8383.

(19) Jaramillo-Quintero, O. A.; Sánchez, R. S.; Rincón, M.; MoraSero, I. Bright Visible-Infrared Light Emitting Diodes Based on Hybrid Halide Perovskite with Spiro-OMeTAD as a Hole Injecting Layer. J. Phys. Chem. Lett. 2015, 6 (10), 1883.

(20) Tan, Z.-K.; Moghaddam, R. S.; Lai, M. L.; Docampo, P.; Higler, R.; Deschler, F.; Price, M.; Sadhanala, A.; Pazos, L. M.; Credgington, D.; et al. Bright Light-Emitting Diodes Based on Organometal Halide Perovskite. Nat. Nanotechnol. 2014, 9 (9), 687-692.
(21) Wong, A. B.; Lai, M.; Eaton, S. W.; Yu, Y.; Lin, E.; Dou, L.; Fu, A.; Yang, P. Growth and Anion Exchange Conversion of $\mathrm{CH}_{3} \mathrm{NH}_{3} \mathrm{PbX}_{3}$ Nanorod Arrays for Light-Emitting Diodes. Nano Lett. 2015, 15, 5519-5524.

(22) Li, G.; Tan, Z. K.; Di, D.; Lai, M. L.; Jiang, L.; Lim, J. H. W.; Friend, R. H.; Greenham, N. C. Efficient Light-Emitting Diodes Based on Nanocrystalline Perovskite in a Dielectric Polymer Matrix. Nano Lett. 2015, 15 (4), 2640-2644.

(23) Walzer, K.; Maennig, B.; Pfeiffer, M.; Leo, K. On Electrically Doped Transport Layers Highly Efficient Organic Devices Based on Electrically Doped Transport Layers. Chem. Rev. 2007, 107 (4), $1233-1271$

(24) Pei, Q.; Yu, G.; Zhang, C.; Yang, Y.; Heeger, A. J. Polymer Light-Emitting Electrochemical Cells. Science 1995, 269 (5227), $1086-1088$

(25) deMello, J. C.; Tessler, N.; Graham, S. C.; Friend, R. H.; C, J.; Tessler, N.; Graham, S. C.; Friend, R. H. Ionic Space-Charge Effects in Polymer Light-Emitting Diodes. Phys. Rev. B: Condens. Matter Mater. Phys. 1998, 57 (20), 12951-12963.

(26) Slinker, J. D.; DeFranco, J. a; Jaquith, M. J.; Silveira, W. R.; Zhong, Y.; Moran-Mirabal, J. M.; Craighead, H. G.; Abruña, H. D.; Marohn, J. a; Malliaras, G. G. Direct Measurement of the ElectricField Distribution in a Light-Emitting Electrochemical Cell. Nat. Mater. 2007, 6 (11), 894-899.

(27) Van Reenen, S.; Matyba, P.; Dzwilewski, A.; Janssen, R. A. J.; Edman, L.; Kemerink, M. A Unifying Model for the Operation of Light-Emitting Electrochemical Cells. J. Am. Chem. Soc. 2010, 132 (39), 13776-13781.

(28) Lenes, M.; Garcia-Belmonte, G.; Tordera, D.; Pertegás, A.; Bisquert, J.; Bolink, H. J. Operating Modes of Sandwiched LightEmitting Electrochemical Cells. Adv. Funct. Mater. 2011, 21 (9), $1581-1586$

(29) Meier, S. B.; Tordera, D.; Pertegás, A.; Roldán-Carmona, C.; Ortí, E.; Bolink, H. J. Light-Emitting Electrochemical Cells: Recent Progress and Future Prospects. Mater. Today 2014, 17 (5), 217-223.

(30) Saidaminov, M. I.; Abdelhady, A. L.; Murali, B.; Alarousu, E.; Burlakov, V. M.; Peng, W.; Dursun, I.; Wang, L.; He, Y.; Maculan, G.; et al. High-Quality Bulk Hybrid Perovskite Single Crystals within Minutes by Inverse Temperature Crystallization. Nat. Commun. 2015, 6 (May), 7586

(31) Andričević, P.; Kollár, M.; Mettan, X.; Náfrádi, B.; Sienkiewicz, A.; Fejes, D.; Hernádi, K.; Forró, L.; Horváth, E. Three-Dimensionally Enlarged Photoelectrodes by a Protogenetic Inclusion of Vertically Aligned Carbon Nanotubes into $\mathrm{CH}_{3} \mathrm{NH}_{3} \mathrm{PbBr}_{3}$ Single Crystals. $J$. Phys. Chem. C 2017, 121 (25), 13549-13556.

(32) Bonard, J.; Salvetat, J.; Stöckli, T.; Forr, L. Field Emission from Carbon Nanotubes: Perspectives for Applications. Appl. Phys. A: Mater. Sci. Process. 1999, 69 (3), 245-254.

(33) Fowler, R. H.; Nordheim, L. Electron Emission in Intense Electric Fields. Proc. R. Soc. London, Ser. A 1928, 119 (781), 173-181.

(34) Yi, H. T.; Wu, X.; Zhu, X.; Podzorov, V. Intrinsic Charge Transport across Phase Transitions in Hybrid Organo-Inorganic Perovskites. Adv. Mater. 2016, 28, 6509-6514.

(35) Dong, H.; Wu, Z.; Xia, B.; Xi, J.; Yuan, F.; Ning, S.; Xiao, L.; Hou, X. Modified Deposition Process of Electron Transport Layer for Efficient Inverted Planar Perovskite Solar Cells. Chem. Commun. 2015, 51 (43), 8986-8989.

(36) Shiraishi, M.; Ata, M. Work Function of Carbon Nanotubes. Carbon 2001, 39 (12), 1913-1917.

(37) Bandiello, E.; Avila, J.; Gil-Escrig, L.; Tekelenburg, E.; Sessolo, M.; Bolink, H. J. Influence of Mobile Ions on the Electroluminescence Characteristics of Methylammonium Lead Iodide Perovskite Diodes. J. Mater. Chem. A 2016, 4 (47), 18614-18620.

(38) Eames, C.; Frost, J. M.; Barnes, P. R. F.; O’Regan, B. C.; Walsh, A.; Islam, M. S. Ionic Transport in Hybrid Lead Iodide Perovskite Solar Cells. Nat. Commun. 2015, 6 (May), 7497.

(39) Almora, O.; Guerrero, A.; Garcia-Belmonte, G. Ionic Charging by Local Imbalance at Interfaces in Hybrid Lead Halide Perovskites. Appl. Phys. Lett. 2016, 108 (4), 043903. 
(40) Zhao, L.; Gao, J.; Lin, Y. L.; Yeh, Y.-W.; Lee, K. M.; Yao, N.; Loo, Y.-L.; Rand, B. P. Electrical Stress Influences the Efficiency of $\mathrm{CH}_{3} \mathrm{NH}_{3} \mathrm{PbI}_{3}$ Perovskite Light Emitting Devices. Adv. Mater. 2017, 29 (24), 1605317.

(41) Li, J.; Bade, S. G. R.; Shan, X.; Yu, Z. Single-Layer LightEmitting Diodes Using Organometal Halide Perovskite/Poly(Ethylene Oxide) Composite Thin Films. Adv. Mater. 2015, 27 (35), 5196-5202.

(42) Wenger, B.; Nayak, P. K.; Wen, X.; Kesava, S. V.; Noel, N. K.; Snaith, H. J. Consolidation of the Optoelectronic Properties of $\mathrm{CH}_{3} \mathrm{NH}_{3} \mathrm{PbBr}_{3}$ Perovskite Single Crystals. Nat. Commun. 2017, 8 (1), 590.

(43) Puscher, B. M. D.; Aygüler, M. F.; Docampo, P.; Costa, R. D. Unveiling the Dynamic Processes in Hybrid Lead Bromide Perovskite Nanoparticle Thin Film Devices. Adv. Energy Mater. 2017, 7 (15), 110.

(44) Zhang, H.; Lin, H.; Liang, C.; Liu, H.; Liang, J.; Zhao, Y.; Zhang, W.; Sun, M.; Xiao, W.; Li, H.; et al. Organic-Inorganic Perovskite Light-Emitting Electrochemical Cells with a Large Capacitance. Adv. Funct. Mater. 2015, 25 (46), 7226-7232.

(45) Sharma, P.; Bhatti, T. S. A Review on Electrochemical DoubleLayer Capacitors. Energy Convers. Manage. 2010, 51 (12), 29012912.

(46) Fresta, E.; Costa, R. D. Beyond Traditional Light-Emitting Electrochemical Cells - a Review of New Device Designs and Emitters. J. Mater. Chem. C 2017, 5 (23), 5643-5675.

(47) Aygüler, M. F.; Weber, M. D.; Puscher, B. M. D.; Medina, D. D.; Docampo, P.; Costa, R. D. Light-Emitting Electrochemical Cells Based on Hybrid Lead Halide Perovskite Nanoparticles. J. Phys. Chem. C 2015, 119 (21), 12047.

(48) Bade, S. G. R.; Li, J.; Shan, X.; Ling, Y.; Tian, Y.; Dilbeck, T.; Besara, T.; Geske, T.; Gao, H.; Ma, B.; et al. Fully Printed Halide Perovskite Light-Emitting Diodes with Silver Nanowire Electrodes. ACS Nano 2016, 10 (2), 1795-1801.

(49) Magrez, A.; Smajda, R.; Seo, J. W.; Horváth, E.; Ribič, P. R.; Andresen, J. C.; Acquaviva, D.; Olariu, A.; Laurenczy, G.; Forró, L. Striking Influence of the Catalyst Support and Its Acid-Base Properties: New Insight into the Growth Mechanism of Carbon Nanotubes. ACS Nano 2011, 5 (5), 3428-3437.

(50) Szabó, A.; Andričević, P.; Pápa, Z.; Gyulavári, T.; Németh, K.; Horváth, E.; Forró, L.; Hernadi, K. Growth of CNT Forests on Titanium Based Layers, Detailed Study of Catalysts. Front. Chem. 2018, 6, 1-9. 